\title{
A ansiedade e seu enfrentamento
}

\section{Lús FillipeV asques da Silva - UnivesidadeSãoFramiso, Itatiba, Brasil}

\author{
Leahy, R. L. (2011). LivedeAnsiecade (V. Figueira, trad.). Porto Alegre: Artmed.
}

A ansiedade e seus transtomos atingem grande parte da população mundial e suas atividades de cotidiano. Diante de tal constatação, o livro escrito por Robert L. Leahy e traduzido por Vinícius Figueira busca apresentar, por meio da abordagem comportamental-cognitiva, informações sobre a ansiedade e formas de enfrentamento para os sujeitos que sofrem desse distúrbio.

Leahy inicia o livro, com agradecimentos aos colegas e amigos que contribuíram para a sua elaboração, destacando Aaron T. Beck, o fundador da psicologia cognitiva, e apresentando a obra, que é dividida em dez capítulos e dez apêndices.

No início do primeiro capítulo, o autor relata 0 caso de uma paciente com ansiedade visando a um melhor entendimento do tema pelos leitores. É descrito um histórico da doença, o raciocínio diagnóstico e formas de tratamento para os transtornos. É um capítulo introdutório aos demais que compõem o livro.

No capitulo dois, Leahy apresenta um histórico de como a ansiedade se desenvolveu no processo evolutivo humano. Compara algumas das características humanas com a maneira com que os gatos vivem, o modo que as pessoas ficam preocupadas com muitas situações e como se importam com o que comunicam com os outros. Ainda nesse capítulo, o autor cria uma pequena história de um homem vivendo na pré-história com vários estereótipos dos transtomos de ansiedade com o intuito de preparar o leitor para os seguintes.

No terceiro capítulo, 0 autor dedica-se às "regras" para se tornar um indivíduo ansioso. 0 terapeuta explica como o cérebro humano reage quando um estímulo causa medo no indivíduo e quais as estratégias cognitivas para enfrentar 0 medo. Apresenta regras para se controlar a ansiedade, visando minimizar ou cessá-la. Além disso, o autor compara 0 cérebro humano aos programas de computadores, a fim de facilitar 0 entendimento do leitor quanto ao processamento de informações.

O quarto capítulo é consagrado ao primeiro transtorno de ansiedade comentado no livro: a Fobia Específica (FE). Leahy usa pacientes que atendeu para exemplificar como uma pessoa fóbica atua no cotidiano. Em geral, o autor apresenta várias informações sobre 0 assunto a fim de esclarecer as dúvidas do leitor leigo. Propõe-se algumas técnicas que são utilizadas no tratamento desse tipo de ansiedade.

O capítulo seguinte conta com a apresentação do Transtorno Obsessivo-Compulsivo (TOC). Mais uma vez 0 autor reúne informações, casos e técnicas, a fim de resolver a angústia de quem está passando pelo distúrbio. Robert Leahy mostra casos que são comuns no cotidiano de qualquer pessoa que se relaciona com colegas, amigos, familiares. Esclarece as questões sobre as crenças irracionais que levam pessoas a se preocuparem e punirem a si mesmos enquanto portadores de TOC.

No sétimo capítulo, o autor tem como objetivo proporcionar o conhecimento ao leitor sobre 0 Transtorno de Ansiedade Generalizada (TAG). Leahy utiliza-se de acontecimentos comuns presentes na vida das pessoas que se preocupam com o trabalho, os problemas de relacionamento com o chefe ou com a família, se os filhos estão seguros ou se há problemas com o cônjuge. Além disso, o autor descreve duas técnicas: 0 mindfillness e a técnica de relaxamento muscular progressivo. Com essas, segundo Leahy, o TAG pode ser minimizado e controlado.

No oitavo capítulo, o autor descreve a respeito do Transtorno de Ansiedade Social (TAS) ou fobia social, um dos transtornos mais comuns na população. Leahy evidencia os pensamentos e impactos que 0 TAS causa na vida dos que padecem desse distúrbio. Comum aos outros capítulos, o terapeuta dispõe de técnicas que ajudam o leitor a enfrentar os problemas no contexto social e quais pensamentos podem estar presentes em cada situação de desconforto que os indivíduos passam.

No nono capítulo, o autor trata do último transtorno de ansiedade comentado, o Transtorno de Estresse Pós-Traumático (TEPT). Apresenta conhecimentos sobre o TEPT e um exercício novo no livro, além dos outros que já haviam sido discutidos anteriormente, para solucionar os problemas das pessoas que sofrem de TEPT. 0 autor confessa que 0 livro pode ser usado para autoajuda, porém o resultado pode ser melhor para aqueles que procurarem um terapeuta cognitivo-comportamental para auxiliar no desconforto. Ainda nesse capítulo o autor apresenta casos de pessoas que sofreram do TEPT por terem passando por alguma experiência desagradável.

O ultimo capítulo é um resumo de todos os principais casos apresentados. É um autorrelato das 
experiências que obteve com os casos e agradece os pacientes por terem dado conhecimento sobre 0 assunto. No fim, Leahy conversa com o leitor, incentivando-o(a) a olhar para si mesmo e procurar 0 tratamento que solucione 0 que está fazendo-o(a) se sentir ansioso(a).

Nos apêndices há informações adicionais acerca de cada transtorno de ansiedade. Dentre os assuntos comentados no apêndice, Leahy orienta como usar técnicas e testes, enfatizando a necessidade de ajuda de um profissional.

A linguagem do livro é formal, porém é voltado para o leitor leigo. Leahy faz uso de vários exemplos, 0 que beneficia na compressão do assunto abordado nos vários capítulos.

De maneira geral, o livro é muito interessante, bem traduzido e escrito. Sendo assim, é uma referência e recomenda-se sua leitura a todos que se interessam pela temática.

Sobre 0 autor:

Luís Fillipe Vasques da Silva é graduando em Psicologia, participa do Programa de Iniciação Científica da Universidade São Francisco e bolsista do CNPq.

Contato com o autor:

Alameda Grécia, 79 - CEP: 12916-060. Bragança Paulista.

Email: luisfillipe5@gmail.com 